\title{
Litotes $^{1}$ - an ironic or polyphonic figure of speech?
}

\author{
Merete Birkelund \\ Aarhus University
}

I shall now therefore humbly propose my own thoughts, which I hope will not be lyable to the least Objection.

(Jonathan Swift. 1729. A Modest Proposal)

\begin{abstract}
According to classical rhetorical traditions, litotes is a rhetorical figure of speech used as a negative statement in order to emphasise the speaker's positive point of view. In this contribution in honour of Sten Vikner, I discuss the function and the semantic features of negative litotes, i.e. a positive statement expressed by negating its opposite. Although some scholars claim that negative litotes does not possess any kind of polyphony, i.e. the idea that an utterance or a text communicates different points of view, I will argue that negative litotes communicates different points of view when used by a speaker for ironic purposes, especially because the presence of a polemic negation in combination with irony can be interpreted in terms of linguistic polyphony.
\end{abstract}

\section{Introduction}

The main focus of this article is to examine the nature of litotes, which has been regarded since ancient times as a rhetorical figure of speech. Latin grammarians define litotes as follows:

[litotes] minus dicit quam significat

[Litotes] says less than it means

The main function of litotes is to soften the meaning of the speaker's utterance, thereby weakening its pragmatic effects. In negative litotes the

1 Litotes' - from Greek 'litotés', literally meaning simplicity or plainness; derivative of

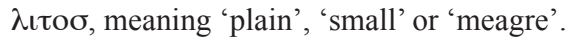

Ken Ramshøj Christensen, Henrik Jørgensen \& Johanna L. Wood (eds.). 2019.

The Sign of the V-Papers in Honour of Sten Vikner.

Dept. of English, School of Communication \& Culture, Aarhus University, pp. 63-75, doi:10.7146/aul.348.89. (C) The author(s). 
morphosyntactic negation is an important element. Negative litotes uses an understatement to emphasize a statement by stating a negative to further affirm a positive, and often incorporates double negatives for effect. The negation downplays, so to speak, the force of the speaker's meaning as in (1):

\section{(1) Peter is not talkative.}

In (1), the speaker's utterance hides the real meaning behind the explicit negative point of view, so what the speaker really means is that 'Peter is (rather) taciturn/reticent/uncommunicative'. Litotes only refers to the negation of one quality while emphasising its opposite. Of course, the negation itself does not imply that the statement should be read as litotic; it can only be a linguistic indication because a correct interpretation depends on the recipient's interpretative skills and the contextual situation in which the speaker presents the statement.

In some contexts, litotes is used by the speaker for ironic purposes, so litotes can be regarded as a form of ironic understatement. Verbal irony is a figure of speech just like litotes. What the two can have in common is that the speaker's statement is the opposite of what (s)he really means. Litotes is often regarded as a special form of verbal irony which represents an implicit meaning and an understatement, but which also represents specific verbal aspects such as the presence of a morphosyntactic negation. It is the combination of the implicit, the understatement, the negation and irony that I take a closer look at in this article. The theoretical framework of the analysis that I propose is linguistic polyphony, which is an important part of French enunciation linguistics. I argue that litotes is a form of verbal irony that does have polyphonic features, just like irony, and that this figure of speech is used for rhetorical and conversational reasons (cf. Grice 1975). First, I give some definitions of litotes and discuss its form and function in section 2. In section 3, there is a discussion of the relationship between litotes and irony. The relationship between litotes and negation, within the theoretical framework of linguistic polyphony that I use in this analysis, is studied in section 4 .

\section{Litotes}

\subsection{Definitions of litotes}

According to traditional definitions, litotes is regarded as a form of understatement which is used by the speaker with the intention of 
presenting something as worse, smaller, less etc. than it really is. Litotes always includes an aspect of negativity. This negative aspect of litotes is found in encyclopedic definitions, e.g. Webster's Encyclopedic Unabridged Dictionary of the English Language, which defines litotes as: "Rhet. understatement, esp. that in which an affirmative is expressed by the negative of its contrary, as in "not bad at all"". The Cambridge Advanced Learner's Dictionary \& Thesaurus also mentions the importance of the presence of a negative statement when suggesting the following definition: "... the use of a negative statement in order to emphasize a positive meaning, for example 'a not inconsiderable amount of money' (= a considerable amount of money)".

The core meaning of litotes is implicit. The speaker's strategy is to make the understatement obvious to the recipient by means of a negative element whose main function is to negate the speaker's statement. The speaker presents a negative point of view, whereas her/his 'real' point of view is implicit, i.e. opposite or contrary to the explicit negative one, for instance the following examples of common expressions from everyday life:

(2) Well, that wasn't the best cocktail party.

(3) This was not a small problem.

By using the litotes in (2) and (3), the speaker has considered the implicit point of view too harsh for a plain expression, so the speaker is 'hiding' her/his implicit point of view behind the explicit point of view in which the morphosyntactic - and polemic in polyphonic terms - negation is present. In this article I argue that examples of litotes like 'Well, that wasn't the best cocktail party' have a polyphonic nature when they function as ironic figures of speech.

\subsection{Form and function of litotes}

To some scholars, litotes is simply a variant of euphemism. For instance, Kerbrat-Orecchioni (1994) claims that litotes should be regarded as a process of mitigation - just like euphemisms, which possess mitigated features. Nevertheless, I claim that the two figures are not phrased in the same verbal manner and do not have the same function. A euphemism actually says less, whereas litotes only pretends to say less with a view to softening a statement. A euphemism designates the representation of something unpleasant by a mitigated expression and is used to refer to 
things and situations that people might find upsetting or harsh, e.g. 'to be economical with the truth' instead of talking about 'a liar'; 'to be between jobs' instead of 'to be unemployed'; 'ethnic cleansing' instead of 'genocide'; whereas negative litotes is often used in more or less fixed negated expressions in which the presence of a morphosyntactic negation is a typical linguistic feature. However, some utterances that resemble litotes are in fact euphemisms, for instance (4):

(4) Peter is not the sharpest pencil in the box.

As already mentioned in the definitions above, litotes involves understatements which the speaker uses with conversational intentions. The presence of a morphosyntactic negation or a negative element is obligatory, and it seems to be the case that the negated element, i.e. the attribute in the most common syntactic structure, has to belong to a semantic paradigm whose semantic meaning is negative, e.g. 'not bad'; 'not unhappy'; 'not stupid', with 'bad', 'unhappy' and 'stupid' being regarded as semantically negative adjectives. The sentences (5), (6) and (7) are examples of litotes in which the negation intensifies the contrastive effect:

(5) This dinner isn't bad. (= This dinner is good)

(6) It's not inedible. (= It's edible)

(7) $\mathrm{He}$ is not a bad singer. (= He is a good singer)

The presence of a negation in litotes might be a sign of an opposite meaning, especially if the negation is regarded as a mathematical and logical sign of subtraction. But this is not always the case, and as Jespersen (1924: 331-332) says:

Language is not mathematics, and $[\ldots]$ a linguistic negative cannot be compared with the sign - (minus) in mathematics; [...] Language has a logic of its own, and in this case its logic has something to recommend it. Whenever two negatives really refer to the same idea or word (as special negatives) the result is invariably positive; this is true of all languages, and applies to such collocations as e.g. not uncommon, not infrequent, not without some fear. The two negatives, however, do not exactly cancel one another in such a way that the result is identical with the simple common, frequent, with some doubt; the longer expression is always weaker: 'this is not unknown to me' or 'I am not ignorant of 
this' means 'I am to some extent aware of it', etc. The psychological reason for this is that the detour through the two mutually destructive negative weakens the mental energy of the listener and implies on the part of the speaker a certain hesitation which is absent from the blunt, outspoken common or known. In the same way I don't deny that he was angry is weaker than I assert, etc.

But why do speakers not just express their real meaning and intentions literally? Jespersen mentioned psychological reasons, but litotes also seems to be used by the speaker for conversational reasons, i.e. as a phenomenon that can be used in utterances which might be face-threatening for either of the two interlocutors. Many examples of litotes are used to refute, to criticise or to reproach. When this is the case, litotes must be interpreted as a conversational phenomenon that is used in verbal interaction as a sign of politeness, a so-called softener (cf. Brown \& Levinson 1987), allowing the speaker to keep her/his face without threatening the interlocutor's negative face.

The idea of weakening or strengthening an utterance is recognised by many scholars and in the rhetorical tradition - for instance by Beauzée, who talks about litotes as a means of concealing the speaker's real intentions the effect is to give the concealed statement more energy and more weight (Le Guern 2011: 56). The French rhetorician Fontanier agrees with Beauzée when he says that [litotes] "au lieu d'affirmer positivement une chose, nie absolument la chose contraire ou la diminue plus ou moins, dans la vue même de donner plus d'énergie et de poids à l'affirmation positive qu'elle déguise." (1968: 133) ('instead of making a positive statement, litotes negates the opposite or diminishes it more or less in order to give more energy and power to the positive statement that it hides'). So apparently, when speakers use litotes, they do not need to say what they really mean but express their meaning by using a verbal negative expression in order to mitigate their point of view by denying the opposite. The result is that the meaning of the utterance becomes stronger, whereas the real meaning remains implicit and understood.

What can be concluded from the different descriptions of litotes outlined above is that the implicit core meaning of litotes is hidden behind the speaker's explicit statement from which it has to be derived. In other words, the implicit meaning is part of a hierarchy. In section 4.3, I argue that it is the idea of such a hierarchy that allows for a polyphonic analysis of litotes. 


\section{Litotes and irony}

According to classical rhetorical traditions, litotes can cover ironic aspects. In this case, the negation has a double function: it intensifies the contrastive effect, and emphasises the speaker's ironic point of view and attitude. To some extent, the meaning and function of litotes and irony are identical: both litotes and irony share the semantic features of divergence between the literal meaning and the real, hidden, implicit meaning. Ever since Quintilian's work ${ }^{2}$, irony has been regarded as a speech act that the speaker uses in order to say the opposite of what she/he really means. In many studies, irony is regarded as antiphrasis. However, like litotes, irony is not always just a case of contradiction and opposite meaning; and the idea of the 'opposite' seems in many situations too naïve and too general. Irony brings about a relation of power between the speaker and the target of irony. Naturally, the interpretation depends on the interrelations between the speaker and the interlocutor who can be the target of the irony, and on the situation and the context in question. In fact, irony is a complex kind of utterance that consists of many different and crucial factors, such as the speaker (the 'ironist') and the target or individuals to whom the irony is addressed. Irony is an action of fake and pretend (Berrendonner (2002) talks about 'singerie') in which the speaker acts as if (s)he is the one who is responsible for the point of view in the utterance, whereas her/ his real meaning is hidden. Irony is far from being an exclusively verbal phenomenon: gestures, facial expressions and intonation are also important if irony is to succeed.

The common feature of litotes and irony is that the speaker does not talk explicitly about an object but talks about it discreetly instead, thus avoiding naming it explicitly. According to Grice, "To be ironical is, among other things, to pretend $[\ldots]$ and while one wants the pretense to be recognized as such, to announce it as a pretense would spoil the effect" (1978: 125). Since litotes avoids precision and clarity, it very often obscures what the speaker really means and (s)he can therefore be accused of insincerity. For example, in (8)(8), if the speaker uses this statement in a situation where Peter has acted or solved a problem or a task in a clever way, the statement can be interpreted as irony - and as litotes.

(8) Peter is not stupid.

2 Marcus Fabius Quintilian lived 35-96 AD. Known for his work Institutio oratoria. 
While the statement in (8) implies that Peter is to some extent 'not stupid', we do not learn whether Peter is 'intelligent', 'very smart' or just 'not quite stupid'. So (8) does not tell us exactly what the speaker really thinks of Peter's intelligence. In other words, our language is very often unclear. In his essay, Politics and the English Language (1946: 7), Orwell goes as far as to talk about insincerity: "The great enemy of clear language is insincerity. When there is a gap between one's real and one's declared aims, one turns, as it were instinctively, to long words and exhausted idioms, like a cuttlefish spurting out ink". In many situations people do not use language in accordance with the four Gricean maxims (Grice 1975), i.e. quantity, quality, relevance and manner which are the rational principles for communication when people follow the cooperative principle in their striving towards effective communication. In the cases in which I am interested here, i.e. negative litotes used as irony, the maxims of quality and quantity are violated because the speaker does not give all the information (s)he is supposed to give (quantity) and (s)he is not truthful according to her/his real meaning or point of view (quality).

\section{Litotes, negation and polyphony}

\subsection{Brief introduction to linguistic polyphony}

As litotes includes the use of negation and can be used for ironic purposes, the combination of irony and negation in litotes constitutes an expression that seems to fit well into a polyphonic analysis. The combination allows a polyphonic analysis of the speaker's role and of the interrelations between the speaker and her/his interlocutor. The first ideas about linguistic polyphony are to be found in Oswald Ducrot's linguistic works (see e.g. Ducrot 1984) and have been developed since then by Nølke, in particular in his ScaPoLine theory published in English in 2017. I have no intention of describing this approach in detail here, but will merely present some of the ideas which it contains.

The central idea of polyphony is that several points of view are conveyed in one utterance, i.e. several discourses are embedded in one single utterance. The meaning of the utterance is produced by superimposing several single discourses for which several speakers are responsible. As a consequence of this hypothesis, the idea of the unity of the speaker is not relevant. 


\subsection{Negation}

Morphosyntactic negation is a typical example of polyphony because it covers/can cover different points of view. These different points of view are ordered in a hierarchy in which there is one dominant point of view belonging to the speaker who is responsible for it. The speaker uses an explicit point of view to respond to an implicit point of view belonging to another speaker, a real person or just an imagined person or individual.

When different points of view are present at the same time in an utterance, we talk about polyphony. According to the theory of linguistic polyphony, morphosyntactic negation can have two different functions:

1) a polemic function which contains two variants:

- a metalinguistic negation

- a proper polemic negation

2) a descriptive function

The two functions differ from each other: the scope for the metalinguistic negation is the form of the utterance because it does not preserve presuppositions. It often has a marked effect, as in example (9):

(9) Peter is not tall, he is a giant. (Nølke 2017: 99)

In this example, not tall is normally expected to mean 'small'. In (9) the scalar predicate which is in the scope of the negation is not reversed, but the speaker is correcting the interlocutor's former utterance. A metalinguistic reading of the negation reveals that the hidden point of view belongs to a real speaker.

The scope of the polemic negation is the utterance. This negation keeps the presupposition: the enunciation houses two contradictory and incompatible points of view, as in example (10):

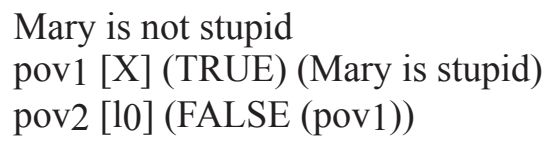

The utterance presents two points of view: an implicit one which defends the content of the positive proposition, pov1, and another, pov2 which holds the negation and for which the speaker of the utterance is responsible. By default, the pov1 is not the speaker's point of view, whereas pov2 
belongs to her/him. The second point of view, pov2, has to be regarded as a comment on the first point of view, pov1, which belongs to an individual who may be a real person or a fictional character or person. The speaker, i.e. the one who is responsible for the negative utterance, rejects, by the use of the negation, a point of view which does not belong to her/him and with which (s)he does not agree. A polemic interpretation of the negation can be stressed by a subsequent sequence as in (10a):

a. Mary is not stupid

... which you might think.

The polemic function of the negation is regarded as the basic (default) interpretation, whereas the other two readings are the result of the influence of contextual factors that can be identified, and are regarded as having a pragmatic meaning.

A descriptive reading of the negation however means that the first point of view is downplayed or even deleted. Its scope is the proposition. It represents one single negative point of view whose only function is to describe a situation or a fact. So, if the negation in example (10) is interpreted as descriptive, the utterance only gives us a description of Mary's intelligence, as in 10b), and the utterance cannot be interpreted as an ironic negative litotes.

b. Mary has the characteristic of being 'non-stupid'.

The utterance can even be negated by yet another negation, giving it a double negation:

$$
\text { c. Mary is not not-stupid. }{ }^{3}
$$

So, the negation not can be interpreted in different ways, but an adequate interpretation depends on different kinds of facts, e.g. more information about the contextual situation, the relationship between the speaker and her/his interlocutor, etc. Without input from such contextual information, it is impossible to distinguish between descriptive and polemic negation.

3 This would undoubtedly be expressed differently in everyday life, e.g. 'Mary is rather clever'. 


\subsection{Negative litotes and irony}

I have already stated that negative litotes involves a statement that is expressed by the negation of its contrast. But, as illustrated by (11), it is not always that simple.

(11) a. She is not unhappy.

b. She is happy.

An utterance like(11))a is not exactly the opposite of the utterance in(11) (11)b, because 'not unhappy' does not necessarily mean that you are 'happy', but that the degree of 'happiness' is situated on a scale somewhere in between the two extremes 'happy' and 'unhappy'. The same analysis goes for example (12):

\section{(12) This wine isn't bad.}

The predicate 'not bad' makes reference to a scalar idea by indicating a particular degree on a qualitative scale. So, when the speaker regards a wine as not bad, the quality of the wine must be somewhere in between the two extremes 'good' and 'bad' on a scale. By using the negative statement (pov2), the speaker denies a positive point of view (pov1), judging the wine as bad but not stating exactly her/his own judgement of the quality of the wine. So the description 'not bad' represents various stages on a quality scale going from 'slightly bad', 'quite good', 'rather good', 'good' and 'really good' to 'excellent'. The interpretation of the speaker's utterance depends on the context and the situation.

A polyphonic analysis of the combination of negative litotes and irony becomes rather complicated because each isolated phenomenon can be regarded as a polyphonic phenomenon in its own right. These phenomena all have in common that they can unfold different points of view, which are organised hierarchically. According to Ducrot's early work on linguistic polyphony and Nølke's ScaPoLine theory, any negative statement refers to a positive one. The speaker who is responsible for the negative statement always distances her/himself from the positive statement, which is attributed to another enunciator, hence the refusal of the unity of the subject/the speaker. The meaning of the combined phenomena, i.e. negation, litotes and irony, is composed of a literal meaning plus a derived meaning. So if they are regarded as representing polyphonic aspects, each phenomenon (litotes and irony) has two points of view: a point of view 
stating something positive, and a second negative point of view denying the positive point of view. Negative litotes used as irony is an 'enunciative double game', which becomes even more complicated owing to the presence of the morphosyntactic negation because it provokes the idea of the presence of two points of view in the utterance. In an example lik 3 ) the speaker's judgement does not appear clearly.

\section{(13) Your dress is not bad.}

What is revealed here is that the speaker expresses an implicit, somewhat positive point of view in spite of the presence of the morphosyntactic negation not. The speaker denies her/his full responsibility for the implicit point of view and is in fact hiding her/his real (positive) judgement by using a fake point of view. The implicit information is scalar, and it is the interlocutor's responsibility to decode the real meaning. The only information available is that the denial 'not bad' means a refusal of 'bad'. The negation not indicates two points of view. This means that the negation here must be polemic because the explicit point of view, pov2, refutes the implicit point of view, pov1. But who is responsible for pov1? According to the polyphonic approach, the speaker who is responsible for the utterance imagines that someone, a real or an imagined person, might have had the point of view that 'the dress is bad', but the point is that it is apparently not an unknown person. The person responsible is most probably the speaker of the utterance. The polyphony revealed here is what is called 'internal polyphony' (cf Nølke 1994), i.e. the speaker of the utterance is responsible for pov1 AND for pov2 as well. ${ }^{4}$

Rossari (2011) claims that the negation in litotes is always descriptive because the speaker is not in opposition to somebody else, but just downplays the message. When negative litotes is used ironically, I claim that the negation must be polemic because the speaker enters into a polyphonic negotiation with her/himself in order to soften her/his real point of view. So the only interpretation of ironic negative litotes is that the speaker does not clarify her/his point of view exactly. In other words, it is the interlocutor who has to decode the speaker's point of view. For argumentative reasons, the speaker softens the pov2 for which (s)he is responsible and avoids threatening the interlocutor's negative face. The speaker does not want to be responsible, and presents instead a point of view with which (s)he negotiates.

4 Cf. Berrendonner's expresssion 'the false naïve' from his article 'Portrait de l'énonciateur en faux naïf' 2002 ('Portrait of the speaker as a false naïve'). 
It is true that negative ironic litotes constitutes a violation of the quality and quantity maxim. The reason why the speaker does not want to be fully responsible must be found in the contextual situation; so, the speaker prefers negative litotes because (s)he wanted to say more than was possible in the given situation. The success of the speaker's ironic intentions when using negative litotes depends on the interlocutor's ability to identify, understand and interpret these intentions.

\section{Can we conclude?}

When the meaning of negative litotes is ironic, the morphosyntactic negation is polemic. The speaker is responsible for the points of view which exist in the polyphonic game in which (s)he plays the antagonist role. In fact, it is the speaker who is responsible for the explicit point of view, but at the same time (s)he is hidden/masked as a false naïve person who is hiding her/his real meaning. But why does the speaker conceal her/his real meaning? Is the speaker insincere, trying to hide her/his realintentions within the communicative act? If this is the reason for the use of negative litotes, it must be a conversational tool that allows her/him to mitigate the communication in order to facilitate a dialogue or conversation which (s)he considers too brutal or too harsh in the situation in question. The function of litotes is to soften the speaker's utterance, but it also tends to be used to avoid open responsibility for the real point of view, precisely because irony can be face-threatening for either of the interlocutors. There is certainly no doubt that irony and litotes can be overused as a conversational phenomenon; and as George Orwell says in a footnote in his essay "Politics and the English Language" (1946:8): "one can cure oneself of the not unformation by memorizing this sentence: A not unblack dog was chasing a not unsmall rabbit across a not ungreen field." 


\section{References}

Anscombre, Jean-Claude \& Oswald Ducrot. 1983. L'argumentation dans la langue. Paris: Mardaga.

Berrendonner, Alain. 2002. Portrait de l'énonciateur en faux naïf. Figures du discours et ambiguité. Semen 15.

Birkelund, Merete \& Henning Nølke. 2013. Ironistik. Ny Forskning i Grammatik 20. 5-30.

Brown, Penelope \& Stephen Levinson. 1978. Politeness. Some universals in language use. Cambridge: Cambridge University Press.

Ducrot, Oswald. 1972. Le dire et le dit. Paris: Les Éditions du Minuit.

Ducrot, Oswald. 1991/1998. Dire et ne pas dire. Principes de sémantique linguistique. Paris: Hermann.

Fontanier, Pierre. 1968. Les Figures du discours. Paris: Les Éditions du Minuit.

Grice, Herbert Paul. 1975. Logic and conversation. In Peter Cole \& Jerry L. Morgen (eds.), Syntax and semantics 3: Speech acts, 41-58. New York: Academic.

Grice, Herbert Paul. 1978. Further notes on logic and conversation. In Peter Cole \& Jerry L. Morgen (eds.), Syntax and semantics 9: Pragmatics. 113-127. New York: Academic.

Horn, Laurence. 2017. Lie-toe-tease: double negatives and unexcluded middles. Philosophical Studies 174. 79-103. doi:10.1007/s11098-015-0509-y

Jaubert, Annie. 2008. Dire et plus ou moins dire. Analyse pragmatique de l'euphémisme et de la litote. Langue Française 160. 105-116.

Jespersen, Otto. 1924. The philosophy of grammar. London: George Allen \& Unwin Ltd.

Le Guern, Michel. 2011. Nicolas Beauzée, «Litote». In André Horak, (ed). La litote. Hommage à Marc Bonhomme. 53-60. Bern: Peter Lang.

Kerbrat-Orecchioni, Catherine. 1994. Rhétorique et pragmatique: les figures revisitées. Langue Française 142. 57-71.

Neuhaus, Laura. 2016. On the relation of irony, understatement, and litotes. Pragmatics \& Cognition 23(1). 117-149.

Nølke, Henning. 1994. Linguistique modulaire: de la forme au sens. LouvainParis: Editions Peeters.

Nølke, Henning. 2017. Linguistic polyphony. The Scandinavian approach: ScaPoLine. Leiden-Brill.

Orwell, George. 1946. Politics and the English language. Horizon. London.

Rossari, Corinne. 2011. La litote est-elle 'trahie' par le sens de sa négation? La litote. Hommage à Marc Bonhomme. In André Horak, (ed). La litote. Hommage à Marc Bonhomme. 115-125. Bern: Peter Lang. 